\title{
THE INCLUSION OF CHILDREN WITH SPECIAL NEEDS IN EARLY CHILDHOOD: CHALLENGES AND DILEMMAS OF KINDERGARTEN TEACHERS
}

\author{
Aviva Dan \\ Dr., Ohalo Academic College for Education and Sport, Katzrin (Israel)
}

\begin{abstract}
The philosophy of inclusion is anchored in the law of Israel, from 2002, stating that all children with special needs have the right to be educated in mainstream kindergartens. As a result of this policy, kindergarten teachers in the mainstream face a complex reality of trying to teach a group of children with very diverse needs that they may not have had any professional training for. This research examines the challenges and dilemmas that face the kindergarten teachers in their daily practices in trying to manage the kindergarten. The literature examines this subject in schools and what is the meaning of such policies from the aspect of schoolteachers and principals, but not from the aspect of kindergarten teachers.

The research is a qualitative study in which five kindergarten teachers in the North of Israel were interviewed. The data analysis was based on categories and show that the kindergarten teachers are facing similar challenges to those of school teachers, lack of specific knowledge on how to teach a group of children in which part of the population has special needs, lack of skills and self confidence in how to deal with such a reality. In addition to the difficulty and lack of self- confidence and lack of skills the kindergarten teachers indicated that they did not feel professional self-efficacy. The contribution of this research can be to rethink the curriculum of training programs for kindergarten to teachers to include the necessary knowledge and practical experience before becoming kindergarten teachers .In addition it is necessary to reexamine the supervisory roles to ensure that a kindergarten teacher who is in the field and has to deal with such a complex problem will receive the professional counselling and resources that is imperative to ensure successful inclusion of children with special needs.
\end{abstract}

Keywords: Early childhood, kindergarten teachers, special needs, inclusion.

\section{Introduction}

Philosophies regarding the ideas of integration of children with special needs in the educational mainstream have changed dramatically over the last twenty or so years. The idea of integration has been recently replaced by the concept of inclusion. In contrast to integration, inclusion demands the adaption of mainstream educational environments to accommodate to every child's needs (Avramidis, Bayliss \& Burden, 2000).

The philosophy of inclusion stems from the philosophy of human rights and that every child has the right to be valued equally, treated with respect and provided with equal opportunities within the main stream system (UN Convention on the Rights of the child 1989 and the UN Standard Rules for the Equalization of Opportunities for Persons with Disabilities, 1993). In early childhood frameworks the policy of inclusion has been translated into different programs (Leatherman \& Niemeyer, 2005). Children with special needs attending kindergarten with children who do not have special needs, children with special needs who attend a kindergarten for children with special needs for most of the week, but for two days will attend a mainstream kindergarten with children who do not have special needs. Each program has its disadvantages and advantages.

One of the greatest advantages of kindergartens for children with special needs is the provision of all the necessary services that are required on site, as opposed to mainstream kindergartens where it is necessary to seek the treatments outside of the kindergarten and often during working hours of the parents, meaning a loss of work days or hours for the parents and the removal of the child from the familiar environment and disturbing their daily schedule. 
According to the literature, factors that affect the success of inclusion practices are the quality of the social interactions and engagement that are facilitated by the staff through natural daily interactions, rather than imported programs (Brown et al., 1999; Malmskog \& Mc Donnell, 1999; Salisbury Galluci, Palombaro, \& Peck, 1995). Collaborative team work between all the professional staff involved in providing services to the children (Brown, Horn, Heiser \& Odem, 1996; Bruder, 2000).

\section{Teachers attitudes to inclusion}

According to the research of Vaughn (1994) the majority of teachers, who did not implement inclusion practices in their classrooms viewed the idea of inclusion in a negative manner. The teachers identified a number of factors that according to them were problematic, class size, inadequate resources, lack of teacher preparation and the extent that the pupils would benefit from inclusion practices. In comparison, research that investigated attitudes of teachers who had actually experienced inclusion showed that the teachers favored the idea of children with special needs being educated in main stream frameworks (Villa et al. 1996). The conclusions indicated that the teacher's positive attitudes were a result of teachers feeling that they had gained professional skills to implement the programs.

In addition, research that was conducted in Australia investigated the daily experiences of mothers and early childhood professionals in an inclusive early childhood program indicated that there are serious limitations in the national policy concerning inclusion in early childhood centers. The few number of successful inclusions were due to the quality of the staff and not as a national policy or guidance for practice (Grace, R. Wedgwood, N., Fenech, M., Mc Conell 2008). In research conducted by Smith \& Smith (2000) which investigated what were the perceptions of kindergarten teachers regarding successful inclusion, the themes that arose indicated a list of factors that are central in promising successful inclusion programs:

I. Training: which included undergraduate teacher preparation, graduate classes, and school district in-service training sessions. Class Load: which included class size, number of students with special needs, severity and range of needs of students, as well as extenuating circumstances, support: which included assistance provided by the regular education paraprofessional assigned to the classroom, by the special education staff, and by the building administration, time: which included the time needed for planning lessons, making adjustments to lessons, making or procuring materials for students with special needs, as well as time needed for collaboration with relevant personnel.

\subsection{Kindergarten teacher's role in successful inclusion}

Inclusion means providing an educational climate that allows each child to develop in all areas and feel supported, accepted and feelings of well- being (Bredkamp and Copple, 1977). Very often the mainstream kindergarten teacher does not have specific training for children with special needs and therefor needs to develop new professional skills ongoing. The kindergarten teacher needs to be responsive and sensitive to the variety of needs at the same time as well as organize a pedagogical program that is developmentally appropriate. Working with children with special needs also demands collaboration with paramedical staff and of course with the child's parents. Very often it is the kindergarten teacher who is the one to identify the child's difficulties and as a result have to support and understand the processes the parents go through, disbelief, anger, depression and eventually, acceptance (Lerner et al. 2003). The kindergarten teacher needs to empower, counsel and support the parents in very often difficult decisions. Placing a child into an inclusive setting is not sufficient to promise that the inclusion will be successful (Vakil, S. Welton, E., O'Conner, B. Kline, L. 2009).

Self- efficacy of Kindergarten teachers as a factor in promising successful inclusion

According to the theory of self-efficacy (Bandura (1997) cognitive processes are central in self-regulating behavior. He suggested that "cognitive processes mediate change, but that cognitive events are induced and altered most readily by experiences of mastery arising from effective performance" (Bandura, 1997, p. 191). Therefor it is imperative for an individual to have the necessary knowledge and skills in addition to feeling self- confidence and a feeling of competency in order to succeed in their efforts to be successful in the inclusion of children with special needs.

Self-efficacy refers to teachers' beliefs that they can bring about desirable changes in pupils' behavior and achievement (Guo, Y., Justice, L. M., Sawyer, B., \& Tompkins, V. 2011). It has been shown in previous research that teachers' feelings of self-efficacy in inclusion situations affect teachers' attitudes, management classroom skills and the students' academic achievements (Ahsan, Sharma and Deppeler, 2012; Gibson and Dembo, 1984; Tschannen-Moran and Hoy, 2001). In a study conducted by Main and Hammond (2008) it was found that preservice teachers that reported high levels of self-efficacy were more successful in managing inclusive programs. 
This research aimed to investigate the dilemmas and challenges facing kindergarten teachers in inclusive kindergartens and how the kindergarten teachers' attitude to inclusion effects the success of inclusion and whether the kindergarten teachers' way of coping with inclusion effects their feeling of professional self-efficacy.

Research Questions

1. What are the challenges and dilemmas facing kindergarten teachers in the inclusion of children with special needs in the mainstream kindergarten?

2. How does the kindergarten teachers' attitudes effect the success of the inclusion?

3. How does dealing with inclusion affect the kindergarten teachers' feeling of professional self- efficacy?

\section{Method}

\subsection{Participants}

The participants in this research were five kindergarten teachers in the north of Israel between the ages of 40-46. All five kindergarten teachers had trained as mainstream kindergarten teachers. Four of the kindergartens were secular and one religious. The number of children in the kindergartens ranged from 20-28. The population of the kindergartens included children with special needs. All kindergartens were in rural settlements. The children with special needs visited the kindergartens on a regular basis. One of the children was enrolled in a part time program at the mainstream kindergarten as well as being a student at the special education kindergarten. The interviews took place in the kindergartens.

This was a qualitative research, qualitative research allows the researcher to gain an insight into thoughts, feelings and personal experiences of the interviewees. The researcher used in depth interviews to enable her to understand the internal world of the kindergarten teachers and get a better understanding about their concerns and dilemmas in teaching children with special needs within a mainstream kindergarten. The data was transcribed and analyzed by content analysis.

\section{Results}

This research aimed to examine the dilemmas and challenges facing kindergarten teachers, the kindergarten teachers attitudes towards inclusion and the effect of inclusion on feelings of professional self- efficacy.

During the interviews the kindergarten teachers expressed their experiences and views considering the success of the inclusive practices and identified the challenges and dilemmas that they faced concerning the inclusion of children with special needs in mainstream kindergartens. The emerging themes that arose from the data revealed the following themes: 1 . Challenges and dilemmas. 2. Attitudes 3. Collaboration with other professionals. 4. Collaboration with the children's parents. 5. Professional self-efficacy. 6. The availability of suitable resources.

\subsection{Challenges and dilemmas}

E. a kindergarten teacher that finished her studies four years ago:

"She demands all my attention, I feel there is her, and the rest of the children. It feels like she demands the same attention as the rest of the kindergarten. All day long I have to make sure that she is given positive feedback, I have to keep my eye on her all day long."

Y. "The kindergarten is a place where he feels comfortable and safe, but I am not sure if it advances him educationally. He likes to be in front of the computer, he is relaxed and quite there, which is good for us and for him. But it feels terrible, a waste ".

"I am there to do the mediating, then the idea works, but it doesn't don't really work, they (the children) are playing near to each other but not with each other. He is feeling good that he is near them and the other children receive the praise from me."

\subsection{Attitudes}

Y." The fact that M. is in our kindergarten, I think that it is a present and I am for inclusion. I am also for the fact that the other children experience being with a child that is different". But I don't know how I would accept another child with physical defects. I would find that much more difficult".

E." I have a humanistic approach, that everyone is equal and everyone gets a chance. I come from that position totally".

E. "We emphasize in our kindergarten the values of consideration for others"

"I believe in integration, and want to bring my kindergarten the idea of integration, how to teach children to accept others who are different, how to bring my staff to include the child with special needs 
into the kindergarten, but it needs to be in small portions of time. It is not impossible in the full-time program but it demands certain conditions. I am totally for integration but it needs to be limited in time and with certain conditions. It cannot be at the expense of the other children."

4.2.1. Collaboration with other professionals. S. "I asked for help from the special education kindergarten, how to mediate with M."

"I asked the psychologist to observe him and he told M parents that the special assistant was not suitable because she did not let M. act freely enough."

E. "I am very happy with the working relationship that I have with the kindergarten teacher from the special education kindergarten. We work together and everything is well organized. The communication with the parents is combined and each one knows her place".

V. "I make sure that I navigate the psychologist's hours in a way that will allow me to answer all the needs in the kindergarten. It is very easy to get into a pattern where all the resources go towards the child with the special needs".

\subsection{Collaboration with the parents}

S. "His mother is very scary, very aggressive and I was lacking in confidence as a new kindergarten teacher with little experience. There was no trust at the beginning".

C. "I never thought of what the parents were going through, I do not have that ability. I am able to understand the parents of other children that arrive cranky in the morning, or are having problems, but I never took the time to think what M.'s parents are going through."

E. "We learnt during the year to trust each other".

"After the Chanuka party 'his mother came up to me and told me how disappointed she was. I remember that was a significant point for me, I had done everything that I could or knew how to do".

4.3.1. Professional self-efficacy. Y. "It is not easy to manage a kindergarten when there is a child with special needs, not even for more experienced kindergarten teachers. Even more so for a kindergarten teacher in her first year".

S. "I did not know how to do this".

S. "In my first year I arrived on the kibbutz, no one prepared me for this, I had no experience or knowledge no one explained to me what is a child with special needs, you have to do this or other things. Today I am more experienced, today M. is in his second year in the kindergarten, I have more knowledge, so does he, he knows what is expected of him."

Y." I go to sleep easily at night and feel that I am fulfilling my professional duties."

\subsection{Resources}

V. "You know we are limited in the number of children that we can ask for special resources. Each year it is becoming more and more difficult to receive the necessary resources. Last year I was able to receive help for children with emotional difficulties, this year impossible".

C. "Inclusion that does not come with resources, or with the necessary professional advise, if it means extra staff or part time programs or professional consultation does not enable us to fulfill the targets of inclusion in a professional way".

\section{Conclusions and discussion}

The philosophy of inclusion comes from a democratic humanistic view of equal rights and opportunities for diverse populations.

The law of special education and inclusion in Israel is based on this agenda. The promotion of human dignity and the aspiration for equal opportunity. (2002) This research investigated the practical side of the implementation of the law from the experiences of kindergarten teachers whom are required to implement this law in their kindergartens. None of the kindergarten teachers who participated in this research had professional training in special education.

To ensure that the inclusion programs are successful it is necessary to provide certain conditions. According to the literature professional training, class load, support and time, and other resources were shown to be influential in effecting the quality of the inclusion programs (Smith \& Smith, 2000). In this present research it was shown that all these factors were thought to be inadequate to allow the kindergarten teachers to feel that they were able to successfully activate the inclusion program, " I don't know to do this".

In conclusion it can be seen that the inclusion of children with special needs within mainstream kindergartens brings with it a complex myriad of dilemmas and challenges for the kindergarten teacher. 
There seems to be a gap between the philosophical, ideological side and the implementation in the field. The researcher recommends that all teacher training programs address this issue and provide professional training in this area to enable future kindergarten teachers to feel professionally capable in being able to implement a program based on knowledge and not just depend on their instincts or trial and error and by so ensure that children with special needs are truly included in the communities that they live and are educated in. This research was limited in the number of kindergarten teachers and the geographical area. It is recommended in future research to increase the population and to include kindergartens from other geographical areas.

\section{References}

Ahsan, M. T., Sharma, U. \& Deppeler, J. M. (2012) Exploring pre-service teachers' perceived teaching-efficacy, attitudes and concerns about inclusive education in Bangladesh.' International Journal of Whole Schooling, 8 (2), pp. 1-20.

Avramidis, E., Bayliss, P., \& Burden, R. (2000). A survey into mainstream teachers' attitudes towards the inclusion of children with special educational needs in the ordinary school in one local education authority. Educational psychology, 20(2), 191-211.

Bandura, A. (1977) 'Self-efficacy: toward a unifying theory of behavioral change.' Psychological Review,84, pp. 191-215.

Bredekamp, S., \& Copple, C. (1997). Developmentally appropriate practices. Washington, DC: National Association for the Education of Young Children (NAEYC).

Brown, W. H., Odom, S. L., Li, S., \& Zercher, C. (1999). Ecobehavioral assessment in early childhood programs: A portrait of preschool inclusion. The Journal of Special Education, 33(3), 138-153.

Brown, W. H., Horn, E. M., Heiser, J. G., \& Odom, S. L. (1996). Project BLEND: An inclusive model of early intervention services. Journal of Early Intervention, 20(4), 364-375.

Bruder, M. B. (2000). Family-centered early intervention: Clarifying our values for the new millennium. Topics in early childhood special education, 20(2), 105-115.

Gibson, S. \& Dembo, M. H. (1984) 'Teacher efficacy: a construct validation.' Journal of Educational Psychology, 76, pp. 569-82.

Grace, R., Llewellyn, G., Wedgwood, N., Fenech, M., \& McConnell, D. (2008). Far from ideal: Everyday experiences of mothers and early childhood professionals negotiating an inclusive early childhood experience in the Australian context. Topics in Early Childhood Special Education, 28(1), 18-30.

Guo, Y., Justice, L. M., Sawyer, B., \& Tompkins, V. (2011). Exploring factors related to preschool teachers' self-efficacy. Teaching and Teacher Education, 27(5), 961-968.

Leatherman1, J. M., \& Niemeyer, J. A. (2005). Teachers' attitudes toward inclusion: Factors influencing classroom practice. Journal of Early Childhood Teacher Education, 26(1), 23-36.

Lerner, J. W., Lowenthal, B., \& Egan, R. W. (2003). Preschool children with special needs: Children at risk and children with disabilities. Boston, MA: Allyn \& Bacon.

Main, S. \&Hammond, L. (2008)'Best practice or most practiced?' Pre-service teachers' beliefs about effective behavior management strategies and reported self-efficacy. 'Australian Journal of Teacher Education, 33(4), pp. 28-39.

Malmskog, S., \& McDonnell, A. P. (1999). Teacher-mediated facilitation of engagement by children with developmental delays in inclusive preschools. Topics in Early Childhood Special Education, 19(4), 203-216.

Salisbury, C. L., Gallucci, C., Palombaro, M. M., \& Peck, C. A. (1995). Strategies that promote social relations among elementary students with and without severe disabilities in inclusive schools. Exceptional Children, 62(2), 125-137.

Smith, M. K., \& Smith, K. E. (2000). "I believe in inclusion, but...": Regular education early childhood teachers' perceptions of successful inclusion. Journal of Research in Childhood Education, 14(2), 161-180.

Tschannen-Moran, M. \& Hoy, A. W. (2001) 'Teacher efficacy: capturing an elusive construct.' Teaching and Teacher Education, 17, pp. 783-805.

Unicef. (1989). Convention on the Rights of the Child.

United Nations. Dept. of Public Information. (1994). The standard rules on the equalization of opportunities for persons with disabilities. United Nations.

Vakil, S., Welton, E., O’Connor, B., \& Kline, L. S. (2009). Inclusion means everyone! The role of the early childhood educator when including young children with autism in the classroom. Early Childhood Education Journal, 36(4), 321.

Villa, R., Thousand, J., Meyers, H., \& Nevin, A. (1996). Teacher and administrator perceptions of heterogeneous education. Exceptional Children, 63(1), 29-45. 